NASA Technical Memorandum 85657

NASA-TM-85657 19830024575

\title{
SUPERPOSITION METHOD FOR ANALYSIS OF FREE-EDGE STRESSES
}

John D. Whitcomb and I, S. Raju

June 1983

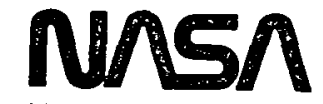

National Aeronautics and Space Administration Langley Research Center Hampton, Virginia 23665

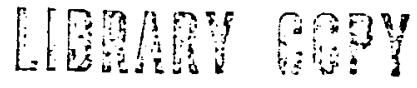

$\therefore \because \% 909$

LMELLY RESEAROH WNTEK LIERARY, NISA

HAKAPTON, VIREINIA 
- 


\section{SUMMARY}

Superposition techniques were used to transform the edge stress problem for composite laminates into a more lucid form. By eliminating loads and stresses not contributing to interlaminar stresses, the essential aspects of the edge stress problem are easily recognized. Transformed problem statements were developed for both mechanical and thermal loads. Also a technique for approximate analysis using a twodimensional plane strain analysis was developed. Conventional quasithree-dimensional analysis was used to evaluate the accuracy of the transformed problems and the approximate two-dimensional analysis. The transformed problems were shown to be exactly equivalent to the original problems. The approximate two-dimensional analysis was found to predict the interlaminar normal and shear stresses reasonably well. 


\section{INTRODUCTION}

Delamination is widely recognized as a critical failure mechanism for laminated composite materials. One cause of delamination is the presence of interlaminar stresses which develop near the free edge of a laminate. Numerous analyses have been developed to calculate interlaminar stresses for the simplest such configuration - the straight free edge of a rectangular laminate (fig. 1). These analyses utilized a variety of techniques including finite difference $[1,2]$, boundary-layer theory [3], perturbation method [4], series solution [5], hybrid finite element $[6,7]$, displacement finite element [8-13], and a mixture of strength of materials, classical laminate theory, and elasticity [14].

In some ways the variety of analyses has improved understanding of the edge stress problem - since each analysis provides its own peculiar interpretation. But for some laminates there is considerable disagreement among the calculated stress distributions obtained using the various techniques (ref. 11). Reference 11 showed that conflicting numerical results can arise from improper treatment of the stress singularity at the free edge. A more fundamental cause of conflicting results is the surprising complexity of the edge stress problem. The problem appears at first fairly simple, yet there are no exact closed form solutions even for simple laminates.

If the edge stress problem can be transformed into a more lucid form, one increases the liklihood of developing reliable, inexpensive analyses. Accordingly, the first objective of this paper was to transform the edge stress problem into a more lucid form. Using superposition techniques, the edge stress problem was transformed into an equivalent problem which is more amenable to intuitive understanding. The second objective was to 
introduce a technique for approximate analysis of the edge stress problem using a two-dimensional (2D) plane strain analysis.

The validity of the superposition technique and the approximate 2D analysis were evaluated by comparing calculated stress distributions with those from a conventional quasi-three-dimensional (Q3D) analysis (i.e., like that in refs. 8-11). These comparisons were made for both mechanical and thermal loading of $[0 / 90]_{S},[ \pm 45]_{S},[90 / 45 / 0 /-45]_{S}$, and $[0 / 90 / \pm 45]_{S}$ laminates.

\section{SYMBOLS}

b half width of the straight-edge laminate, $m$

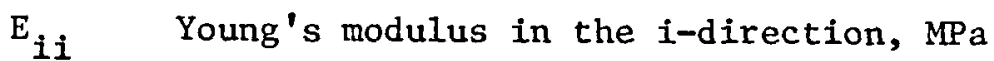

$\mathrm{F}_{\mathrm{x}} \quad$ total force in the $\mathrm{x}$-direction, $\mathrm{N}$

$\mathrm{G}_{\text {ij }}$ shear moduli, MPa

h ply thickness, m

$\Delta \mathrm{T} \quad$ temperature change, ${ }^{\circ} \mathrm{K}$

$\mathrm{U}, \mathrm{V}, \mathrm{W}$ displacement functions, $\mathrm{m}$

$u, v, w$ displacements in $x, y$, and $z$ directions, respectively, $m$

$\mathrm{x}, \mathrm{y}, \mathrm{z}$ Cartesian coordinates, $\mathrm{m}$

$\alpha_{i} \quad$ coefficients of thermal expansion in the i-direction, ${ }^{\circ} K^{-1}$

$\varepsilon_{0} \quad$ uniform axial strain imposed on the laminate, specified to be $\varepsilon_{\mathrm{o}}=.001$

$\theta \quad$ ply fiber angle, deg

$\nu_{i j} \quad$ Poisson's ratios

$\{\sigma\} \quad$ Cartesian stresses, $\sigma_{x}, \sigma_{y}, \sigma_{z}, \sigma_{x y}, \sigma_{y z}, \sigma_{z x}, \mathrm{MPa}$

Subscripts

$i, j \quad i, j=1,2,3$

$1,2,3$ longitudinal, transverse, and thickness directions of a zerodegree ply 
DESCRIPTION OF THE EDGE STRESS PROBLEM

Figure 1 shows the configuration studied, a long rectangular laminate subjected to axial loading. Away from the ends where the loads are applied, the displacements at any $x=$ constant plane can be expressed as (refs. 1-12)

$$
\begin{array}{ll}
u(x, y, z)=\varepsilon_{0} x+U(y, z) \\
v(x, y, z)= & v(y, z) \\
w(x, y, z)= & W(y, z)
\end{array}
$$

The $\varepsilon_{0}$ is the uniform axial strain and $U, V$, and $W$ are functions of $y$ and $z$ only. Equation (1) describes a "quasi-three-dimensional" (Q3D) problem. The modifier "quasi" is used because there are displacements in three directions, but the gradients of $U, V$, and $W$ with respect to the $x$-coordinate are zero.

For mechanical loading, the uniform axial strain $\varepsilon_{0}$ in eq. (1) is specified. For thermal loads the laminate is subjected to a temperature change $\Delta \mathrm{T}$; for this case the magnitude of $\varepsilon_{0}$ in eq. (1) is unknown and is determined as a part of the solution.

Each ply was idealized as a homogeneous, elastic orthotropic material with the following properties:

$$
\begin{array}{lll}
E_{11}=138 \mathrm{GPa} & \left(20.0 * 10^{6} \mathrm{psi}\right) \\
\mathrm{E}_{22}=\mathrm{E}_{33}=14.5 \mathrm{GPa} & \left(2.10 * 10^{6} \mathrm{psi}\right) \\
\mathrm{G}_{12}=\mathrm{G}_{13}=\mathrm{G}_{23}=5.86 \mathrm{GPa} & \left(0.850 * 10^{6} \mathrm{psi}\right) \\
v_{12}=v_{13}=v_{23}=0.21 & \\
\alpha_{1}=0.360 * 10^{-6} \mathrm{~m} / \mathrm{m} /{ }^{\circ} \mathrm{K} & \left(.200 * 10^{-6} \mathrm{in} / \mathrm{in} /{ }^{\circ} \mathrm{F}\right) \\
\alpha_{2}=\alpha_{3}=28.8 * 10^{-6} \mathrm{~m} / \mathrm{m} /{ }^{\circ} \mathrm{K} & \left(16.0 * 10^{-6} \mathrm{in} / \mathrm{in} /{ }^{\circ} \mathrm{F}\right)
\end{array}
$$


The subscripts 1,2 , and 3 correspond to the longitudinal, transverse, and thickness directions, respectively, of a zero-degree ply.

\section{ANALYSIS}

First, the edge stress problems for mechanical and thermal loads rill be transformed using superposition techniques. Advantages of the recast problems will then be discussed. Finally, the finite element analyses used in the study will be described.

\section{Transformed Edge Stress Problem}

Mechanical Loads -

The way that superposition is used to obtain a free surface is the key characteristic of the transformed edge stress problem. The first step in obtaining a free surface by superposition is to develop a methodology for replacing part of the laminate using equivalent tractions. Figure 2 illustrates the methodology for mechanical loads. Figure 2(a) shows an infinite laminate subjected to uniform axial strain $\varepsilon_{0}$. The laminate is symmetric about $z=0$, so only one-fourth of the laminate is shown. To account for the rest of the laminate, $v$ and $w$ are prescribed to be zero along $y=0$ and $z=0$, respectively. To obtain a finite-width laminate, a cut is made along the plane $\operatorname{ABCD}(i . e ., y=b$ ). Because the original laminate is wide, classical laminate theory (CLT) is valid everywhere. Hence, the effect of the material in the volume $y \geq b$ can be simulated by applying the CLT tractions on the plane ABCD (see fig. 2(b)).

To obtain a finite width laminate with a free surface $A B C D$, another load system is added to that in fig. 2(b). These two load systems are shown in fig. 3. Figure 3(a) shows the CLT tractions from fig. 2(b). Figure $3(\mathrm{~b})$ shows the new load system, which consists of tractions that 
are of the same magnitude but of opposite sign to those in fig. 3(a). Also the configuration in fig. $3(\mathrm{~b})$ has the constraint $\varepsilon_{\mathrm{x}}=0$. Figure 3(c) represents a finite width laminate subjected to the uniform axial strain $\varepsilon_{\mathrm{o}}$.

As stated earlier, CLT is valid for the configuration in fig. 3(a). Therefore, the configuration in $\mathrm{fig} .3(\mathrm{a})$ has no interlaminar stresses. Hence, the interlaminar stresses for the finite width laminate in figure 3(c) are identical to those for the configuration in fig. 3(b). Therefore, fig. 3(b) represents the transformed edge stress problem.

Thermal Loads -

As for the mechanical load problem, $\varepsilon_{\mathrm{x}}$ is constant throughout the laminate. However, the magnitude of $\varepsilon_{\mathrm{x}}$ is not known for the thermal problem and must be determined as part of the solution.

Except for very narrow laminates, the uniform axial strain $\varepsilon_{0}$ is very nearly equal to that predicted by CLT [13]. If $\varepsilon_{0}$ is assumed to equal the CLT value, $\varepsilon_{\text {olCLT}}$, then the thermal loads problem can be treated in the same manner as the mechanical load problem. As shown in fig. 4 the thermal problem can be expressed as the superposition of a laminate with CLT tractions (fig. 4(a)) and another problem with the opposite edge tractions (fig. 4(b)). Since the laminate theory problem (fig. 4(a)) has no interlaminar stresses, fig. $4(\mathrm{~b})$ is the transformed interlaminar edgestress problem for thermal loads. The only difference between the thermal (fig. 3(b)) and mechanical (fig. 4(b)) edge-stress problems is the magnitude distribution of the edge tractions, which are given by CLT. Hence, there is no fundamental difference between interlaminar stresses due to thermal and mechanical loads. For the special case of symmetric four-ply laminates, the CLT stresses for the interior plies are the negative of the 
stresses in the surface plies, regardless of the type of loading. Hence, for these laminates the interlaminar stresses for thermal and mechanical loads would differ only by a scale factor.

For very narrow laminates, the more rigorous approach illustrated in fig. 5 is used. The thermal problem, fig. 5(c), is decomposed into two sub-problems. One sub-problem (fig. 5(a)) includes a temperature change $\Delta \mathrm{T}$ and a constraint $\varepsilon_{\mathrm{x}}=0$. The other sub-problem (fig. 5(b)) includes no temperature change, but there is a uniform axial strain $\varepsilon_{\mathrm{x}}=1$. The total solution for the thermal problem in fig. $5(\mathrm{c})$ is obtained by scaling the solution for the second sub-problem by the actual axial $\operatorname{strain} \varepsilon_{0}$ and adding it to the solution for the first sub-problem. Determination of the actual $\varepsilon_{0}$ is based on the condition that the total axial force from the two sub-problems is zero. The axial forces from the two sub-problems are $\mathrm{F}_{\mathrm{x} 1}$ and $\mathrm{F}_{\mathrm{x} 2} \cdot$ Hence,

$$
\begin{aligned}
& F_{x 1}+\varepsilon_{0} F_{x 2}=0 \\
& \text { or } \varepsilon_{0}=-\frac{F_{x 1}}{F_{x 2}}
\end{aligned}
$$

The problem in fig. 5(b) is simply the mechanical load problem described in the previous section. Hence, it can be transformed as the configuration in fig. 3(b). The problem in fig. 5(a) can be approached just like the mechanical load problem in fig. 3, except the tractions defined using CLT correspond to the condition $\varepsilon_{\mathrm{x}}=0$ and a temperature change $\Delta \mathrm{T}$. 
Advantages of Transformed Edge-Stress Problems -

Transforming the edge-stress problem as shown in figs. 3 and 5 has several advantages. By eliminating the laminate theory solution, tractions and stresses not contributing to interlaminar stresses are eliminated. In the transformed problem, the tractions are applied in the area of interest (i.e., where the interlaminar stresses exist) instead of remotely. This clarifies the relationship between the applied tractions and the interlaminar stresses. Since these tractions are determined using CLT, the relationship between CLT stresses and interlaminar stresses is clarified. Finally, the transformed problems eliminate the ambiguity about the relationship between mechanical and thermal loads and the interlaminar stresses. As shown in the previous section, any difference between the effects of mechanical and thermal loads can be explained using laminate theory.

\section{Finite Element Analysis}

Three types of displacement based finite element analyses were used: a 2D analysis and two versions of a Q3D analysis - a conventional Q3D and a Q3D analysis of the transformed edge-stress problem. [Herein, the Q3D analysis applied to the transformed edge-stress problem will be referred to as the superposition Q3D analysis.] The 2D analysis had two degrees of freedom per node. The Q3D analyses had three degrees of freedom per node. The 2D analysis was straightforward, so it will not be described further.

Both Q3D analyses used stiffness matrices like that documented in refs. 8-12. The difference between the two Q3D analyses was the load vector used by each analysis. The conventional Q3D analysis derived the load vector by treating the uniform axial strain $\varepsilon_{0}$ and thermal loads as initial strains. This resulted in loads for all nodes throughout the 
finite element model. In the superposition Q3D analysis loads were applied only for the nodes along $y=b$. These loads were calculated using the tractions (described earlier) which were obtained from CLT.

Because of symmetries only one quarter of a representative $\mathbf{x}=$ constant plane was modeled (fig. 1). Figure 6 shows a typical finite element model for the $[0 / 90]_{s}$ laminate. The model had 775 nodes and 720 four-node isoparametric quadrilatera1s. Similar models were used for

the $[ \pm 45]_{s}$ and quasi-isotropic laminates. The $[0 / 90]_{S}$ and $[ \pm 45]_{S}$ laminates had a laminate width to ply thickness ratio $\mathrm{b} / \mathrm{h}$ of 18.25 ; for the quasiisotropic laminates $b / h$ was 36.5 . To enforce symmetry conditions, the displacement functions $U$ and $V$ were prescribed as zero along $y=0$ and the displacement $W$ was prescribed as zero along $z=0$.

\section{RESULTS AND DISCUSSION}

First, the procedure for analyzing the transformed edge-stress problems for mechanical and thermal loads will be illustrated. Next, the validity of the transformed problems will be evaluated by comparison of stress distributions with those from a conventional Q3D analysis. Finally, an approximate 2D analysis will be described and evaluated.

\section{Mechanical Loads}

In this section the transformed mechanical load problems for $[0 / 90]_{s}$, $[ \pm 45]_{S}$, and $[90 / 45 / 0 /-45]_{S}$ laminates are 11lustrated. The basic problem, as described earlier, can be expressed as the transformed configuration shown in fig. 3(b). The tractions in the figure were calculated using CLT. Figure 7 shows these tractions for $[0 / 90]_{S}$ and $[ \pm 45]_{S}$ laminates. For the $[0 / 90]_{S}$ laminate the shear traction is zero (since the CLT shear stress $\sigma_{x y}$ is zero), so the only tractions are in the $y$-direction. Since there 
is no traction in the $\mathrm{x}$-direction, the problem reduces to a $2 \mathrm{D}$ plane strain problem. Accordingly, a 2D finite element analysis was used to calculate the interlaminar stresses. Figure 8 shows the $\sigma_{z}$ distributions along the $0 / 90$ interface $(z=h)$ obtained with the 2D analysis and the conventional Q3D analysis. The $\sigma_{z}$ distributions from the two analyses agreed identically.

For the $[ \pm 45]_{s}$ laminate the traction normal to the edge is zero. However, because of shear-extension coupling, CLT predicts nonzero $\sigma_{x y}$ stresses. Hence, tractions are applied in the $\mathrm{x}$-direction (see fig. 7). Because of these loads in the $x$-direction a Q3D analysis was required. Figure 9 shows $\sigma_{z}$ and $\sigma_{\mathrm{xz}}$ distributions obtained with the superposition Q3D analysis and the conventiona1 Q3D analysis. Again the $\sigma_{z}$ and $\sigma_{x z}$ distributions from the two analyses agreed identically. Analysis of the quasi-isotropic laminate $[90 / 45 / 0 /-45]_{s}$ differs from that for the four-ply laminates in that CLT predicts both $\sigma_{y}$ and $\sigma_{x y}$ stresses, resulting in tractions in both the $y$ - and $x$-directions, respectively. These tractions are shown in $\mathrm{fig}$. 10. Using these tractions the laminate was analyzed with the superposition Q3D analysis. Figures 11 and 12 show calculated $\sigma_{z}$ and $\sigma_{y z}$ distributions along the interfaces $z=0$ and $z=3 h$, respectively. These are the interfaces where $\sigma_{z}$ and $\sigma_{\mathrm{yz}}$ are maximum. The results agreed identically with the conventional Q3D analysis, therefore only a single curve is shown. The symbols in figs. 11 and 12 are from an approximate analysis and will be discussed in a later section.

\section{Thermal Loads}

The analysis section described two procedures for analyzing the thermal loads problem. The first procedure dissects the problem into two 
sub-problems (see fig. 4). When superposition Q3D analysis was applied to each sub-problem, the calculated stresses were identical to the results obtained using conventional Q3D analysis. The second procedure, outlined in fig. 5, assumes the uniform axial strain $\varepsilon_{0}$ is the same as that given by laminate theory. For an infinitely wide laminate $\varepsilon_{0}$ is, in fact, exactly equal to $\left.\varepsilon_{\mathrm{o}}\right|_{\mathrm{CLT}}$. But for narrow laminates there is a difference. For $b / h=18.25$, the CLT and actual (i.e., calculated from eq. (2)) values of $\varepsilon_{\mathrm{o}}$ are $3.505 \times 10^{-6} /{ }^{\circ} \mathrm{K}$ and $3.468 \times 10^{-6} /{ }^{\circ} \mathrm{K}$, respectively, for a $[0 / 90]_{\mathrm{S}}$ laminate and $3.505 \times 10^{-6} /{ }^{\circ} \mathrm{K}$ and $3.930 \times 10^{-6} /{ }^{\circ} \mathrm{K}$, respectively for a $[ \pm 45]_{S}$ laminate. The difference between the actual and the CLT values of $\varepsilon_{0}$ is greater for the $[ \pm 45]_{S}$ laminate and is about $11 \%$. However, the differences between the calculated interlaminar stresses $\sigma_{z}$ and $\sigma_{x z}$ using the actual and CLT values of $\varepsilon_{0}$ were insignificant. Figure 13 shows the close agreement for $\sigma_{z}$. Apparently the interlaminar stresses due to thermal loads are not very sensitive to errors in estimating the uniform axial strain. Quasi-isotropic laminates were also analyzed using the two procedures from figs. 4 and 5 . As was the case for the four-ply laminates, approximating $\varepsilon_{0}$ by $\varepsilon_{\mathrm{o}} / \mathrm{CLT}$ did not significantly affect the calculated interlaminar stresses.

Comparison of figs. 8, 9, and 13 reveals the similarity of the interlaminar stress distributions for mechanical and thermal loads for symmetric four-ply laminates. For each laminate, the distributions due to mechanical and thermal loads only differ by a scale factor. This similarity was predicted earlier in the analysis section.

\section{Approximate 2D Analysis}

For the special case of a laminate with only 0 and $90 \mathrm{deg}$ plies, any $x=$ constant plane (fig. 1) remains planar after deformation. Hence, a 2D 
analysis is sufficient. But for general laminates with angle plies, the deformation of an $\mathrm{x}=$ constant plane is not planar; $1 . e .$, the plane warps under load. This is caused by the shear-extension coupling of the angle plies. Therefore, in general all three displacements $u, v$, and $w$ must be considered. This is typically accomplished by using a Q3D analysis. However, the Q3D problem can be reduced to a 2D plane strain problem by imposing the constraint $\varepsilon_{x y}=0$ in the constitutive relations for each of the angle plies. The modified relations exhibit no shear-extension coupling. If the modified constitutive relations are used, $x=$ constant planes remain planar after deformation. Hence, a $2 \mathrm{D}$ analysis is appropriate. For $[ \pm \theta]_{S}$ laminates forcing $\varepsilon_{x y}=0$ eliminates the source of interlaminar stresses, so the $2 \mathrm{D}$ analysis is not useful.

For quasi-isotropic or other complicated laminates, however, imposing the constraint $\varepsilon_{\mathrm{xy}}=0$ does not eliminate all sources of interlaminar stresses (except for $\sigma_{z x}$, which becomes identically zero). This is because the mismatches in Poisson's ratios and in thermal expansion coefficients, which cause interlaminar stresses, are not eliminated. Hence, it was hypothesized that the interlaminar stresses $\sigma_{z}$ and $\sigma_{y z}$ could be estimated with a 2D analysis of the transformed edge-stress problem.

The approximate 2D analysis and Q3D analyses were used to calculate interlaminar stresses for two quasi-isotropic laminates $\left[(90 / 45 / 0 /-45)_{\mathrm{s}}\right.$ and $\left.(0 / 90 / \pm 45)_{S}\right]$ subjected to mechanical and thermal loads. Because the accuracy of the 2D analysis was similar for the two laminates, only the results for the $(90 / 45 / 0 /-45)$ s laminate will be presented here. The edge tractions for the superposition Q3D analysis of the $(90 / 45 / 0 /-45)$ s laminate were presented earlier in fig. 10. For the approximate 2D analysis, the $\mathrm{x}$-direction tractions in $\mathrm{fig}$. 10 were set equal to zero. 
The 2D analysis calculated the normal stress $\sigma_{z}$ quite accurately along the interface where $\sigma_{z}$ was largest for mechanical and thermal loads, as shown in figs. 11 and 14. In these figures the solid lines indicate results from the conventional Q3D analysis and the symbols indicate results from the approximate 2D analysis. Along other interfaces where $\sigma_{z}$ was not as large, the accuracy was not as good. A typical case is shown in fig. 15. Note, however, that in fig. 15 the peak value of $\sigma_{z}$ along the interface is calculated with reasonable accuracy. The interlaminar shear stress $\sigma_{\mathrm{yz}}$ was calculated fairly well at a11 interfaces. Figure 12 shows a typical $\sigma_{y z}$ distribution.

The approximate 2D analysis predicts the $\sigma_{z}$ and $\sigma_{y z}$ distribution reasonably accurately. Since computer programs for 2D stress analysis are both less expensive to use and more readily available than those for Q3D analysis, the approximate $2 \mathrm{D}$ analysis of edge stresses may be a viable alternative to Q3D analysis, which is more expensive and which requires specialized computer programs.

\section{CONCLUSIONS}

Superposition principles were used to transform the edge-stress problem into an equivalent problem which is more amenable to an intuitive understanding. Transformed problems were described for both mechanical and thermal loads. The validity of the recast problems was evaluated by comparing calculated stresses with those from a conventional quasi-threedimensional (Q3D) analysis. To further simplify the edge-stress analysis, an approximate two-dimensional (2D) analysis was developed and evaluated. Based on the results presented, the following conclusions were reached:

1. The transformed edge-stress problems obtained using superposition principles are exactly equivalent to the original problems. 
2. The transformed problems are conceptually simpler because (a) tractions and stresses not contributing to interlaminar stresses are eliminated and (b) tractions are applied in the area of interest (i.e., where interlaminar stresses develop) instead of remotely.

3. The transformed problems show clearly that for symmetric fourply laminates interlaminar stresses due to mechanical loads differ only by a scale factor from those caused by thermal loads. Furthermore, for general laminates the differences in the interlaminar stresses for mechanical and thermal loads can be explained using CLT.

4. The approximate $2 \mathrm{D}$ analysis predicts the interlaminar normal and shear stresses reasonably well. Hence, it may be a viable alternative to the more expensive and less readily available Q3D analysis. 


\section{REFERENCES}

1. Pipes, R. Byron; and Pagano, N. J.: Interlaminar Stresses in Composite Laminates Under Uniform Axial Extension. J. Compos. Mater., vol. 4, Oct. 1970, pp. 538- 548.

2. Pipes, R. B.: Interlaminar Stresses in Composite Laminates. AFML-TR-72-18, U.S. Air Force, May 1972. (Available from DTIC as $\mathrm{AD} 776$ 053.)

3. Tang, S.; and Levy, A.: A Boundary-Layer Theory - Part II: Extension of Laminated Finite Strip. J. Compos. Mater., vol. 9, Jan. 1975, pp. 42-52.

4. Hsu, Peter W.; and Herakovich, Car1 T.: Edge Effects in Angle-Ply Composite Laminates. J. Compos. Mater., vol. 11, Oct. 1977, pp. 422-428.

5. Wang, James T. S.; and Dickson, John N.: Interlaminar Stresses in Symmetric Composite Laminates. J. Compos. Mater., vol. 12, Oct. 1978, pp. 390-402.

6. Rybicki, E. F.: Approximate Three-Dimensional Solutions for Symmetric Laminates Under Inplane Loading. J. Compos. Mater., vol. 5, July 1971, pp. 354-360.

7. Spilker, Robert L.; and Chou, S. C.: Edge Effects in Symmetric Composite Laminates: Importance of Satisfying the Traction-FreeEdge Condition. J. Compos. Mater., vol. 14, Jan. 1980, pp. 2-20.

8. Wang, A. S. D.; and Crossman, Frank W.: Some New Results on Edge Effect in Symmetric Composite Laminates. J. Compos. Mater., vol. 11, Jan. 1977, pp. 92-106.

9. Herkovich, C. T.; Nagarkar, A.; and O'Brien, D. A.: Failure Analysis of Composite Laminates With Free Edges. Modern Developments in Composite Materials and Structures, J. R. Vinson, ed., American Soc. Mech. Eng., 1979, pp. 53-66.

10. Raju, I. S.; and Crews, J. H., Jr.: Interlaminar Stress Singularities at a Straight Free Edge in Composite Laminates. Computers and Structures, vol. 14, no. 1-2, 1981, pp. 21-28.

11. Raju, I. S.; Whitcomb, J. D.; and Goree, J. G.: A New Look at Numerical Analyses of Free-Edge Stresses in Composite Laminates. NASA TP-1751, Dec. 1980.

12. Whitcomb, J. D.; Raju, I. S.; and Goree, J. G.: Reliability of the Finite Element Method for Calculating Free-Edge Stresses in Composite Laminates, Computers and Structures, vo1. 15, no. 1, 1982, pp. 23-37. 
13. Wang, A. S. D.; and Crossman, F.: Edge Effects on Laterally Therma1ly Induced Stresses in Composite Laminates, J. Comp. Mater., vol. 11, July 1977, pp. 300-312.

14. Pagano, N. J.; and Pipes, R. Byron: The Influence of Stacking Sequence on Laminate Strength, J. Comp. Mater., vo1. 5, 1971, pp. 50-57. 


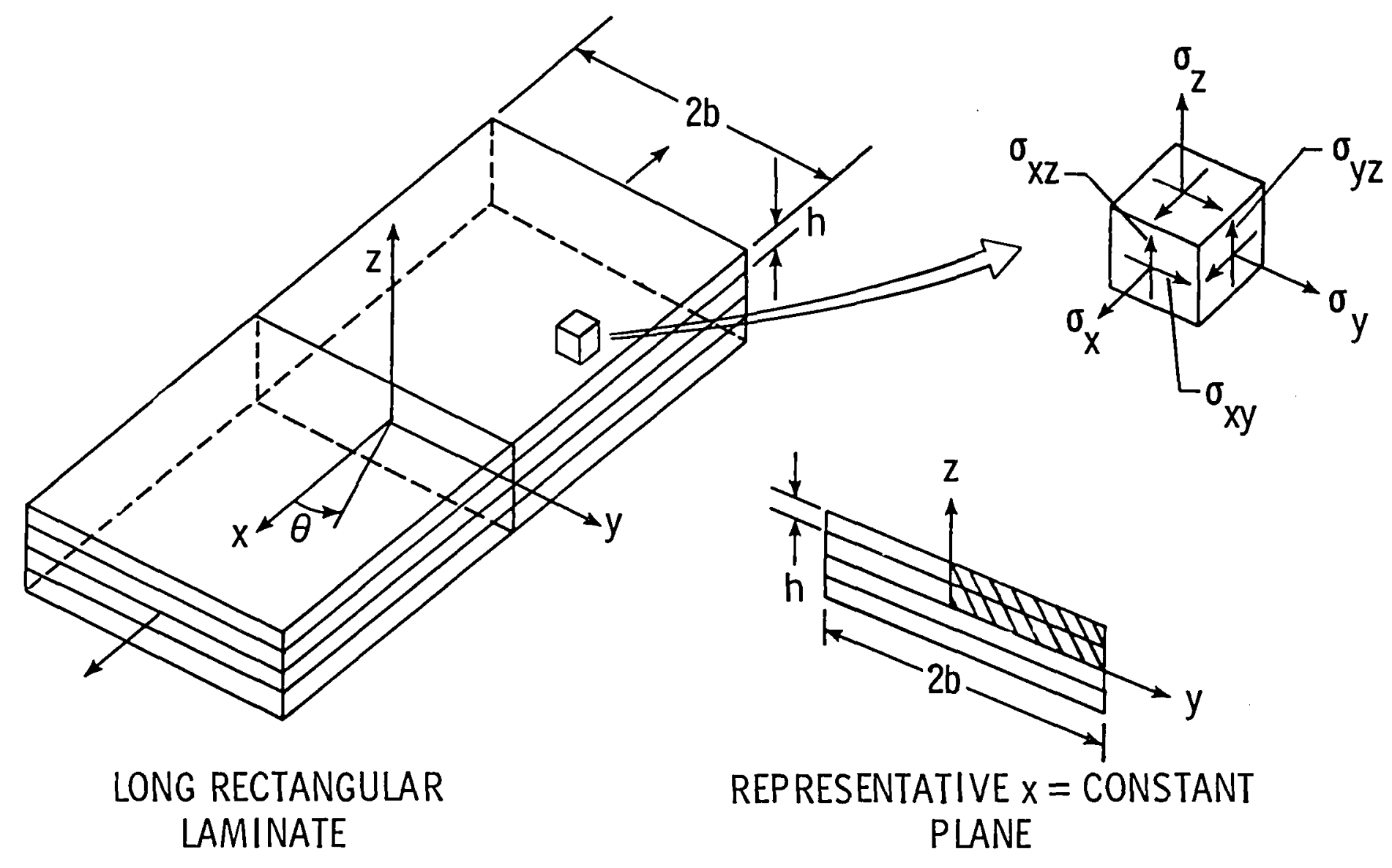

Fig. 1--Laminate configuration. 


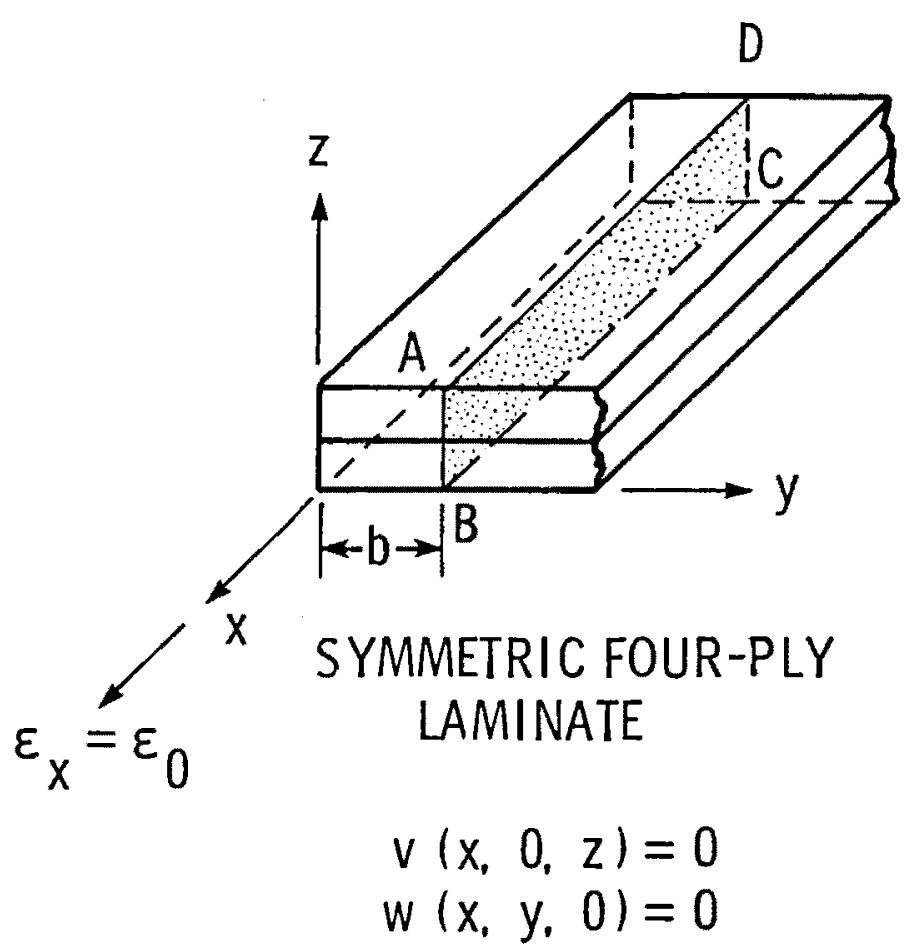

(a)

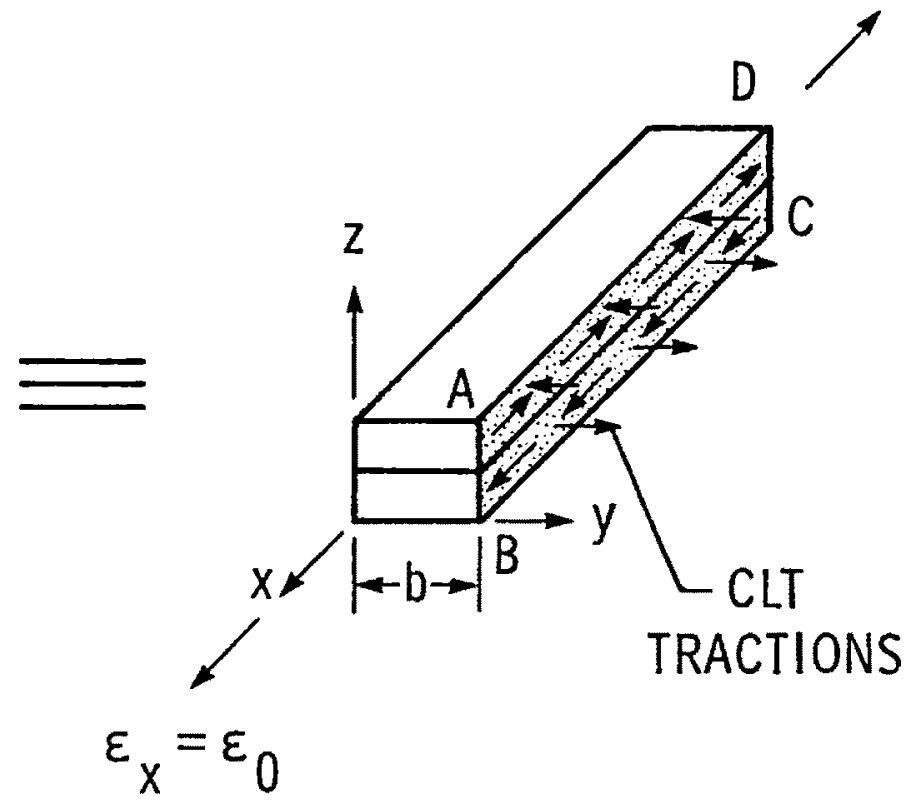

$\begin{array}{lll}v(x, 0, z) & =0 \\ w(x, y, & 0)=0\end{array}$

(b)

Fig. 2--Procedure for replacing part of a laminate with equivalent tractions. 


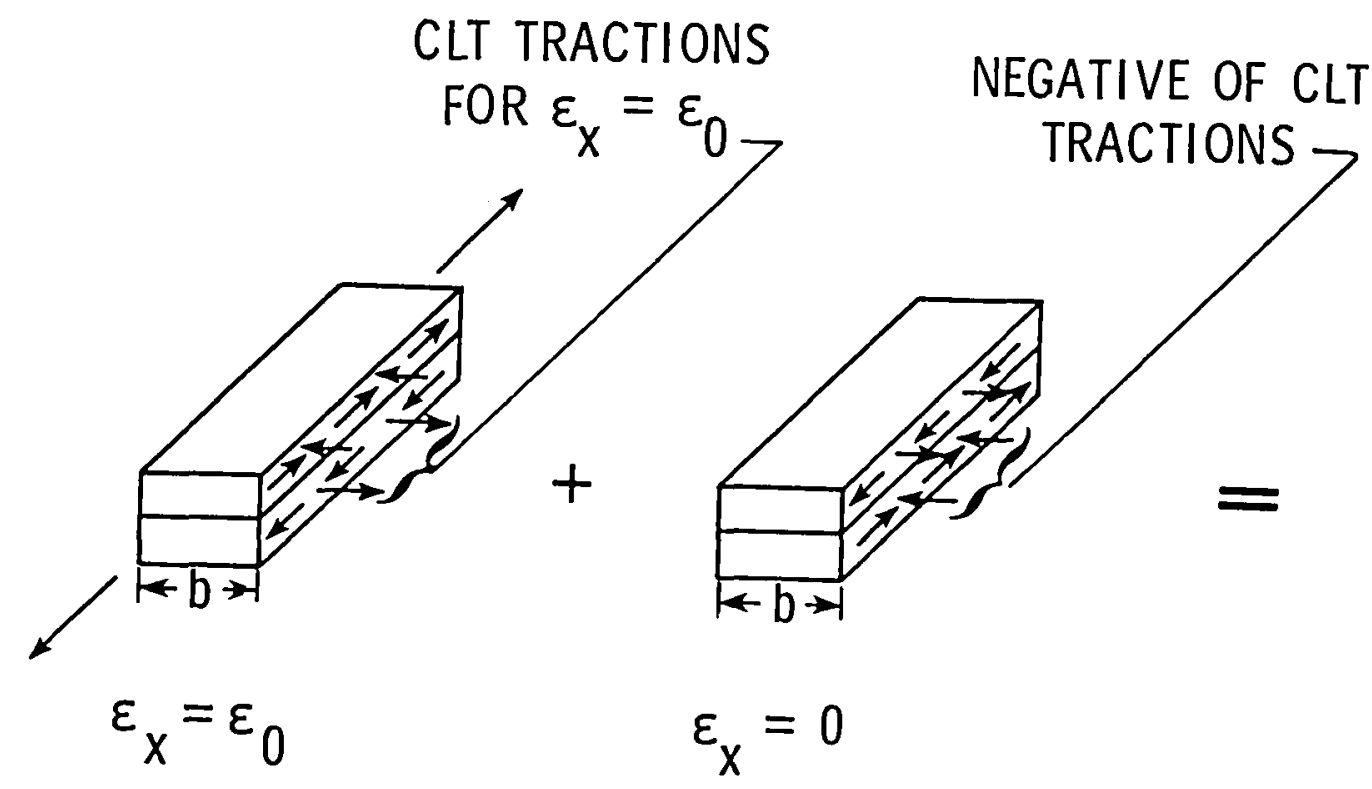

(a) (b)

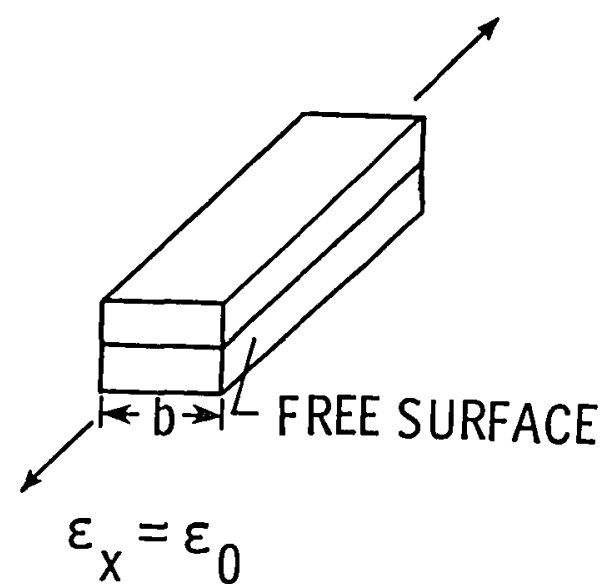

(c)

Fig. 3--Superposition technique for analysis of finite-width laminate. 


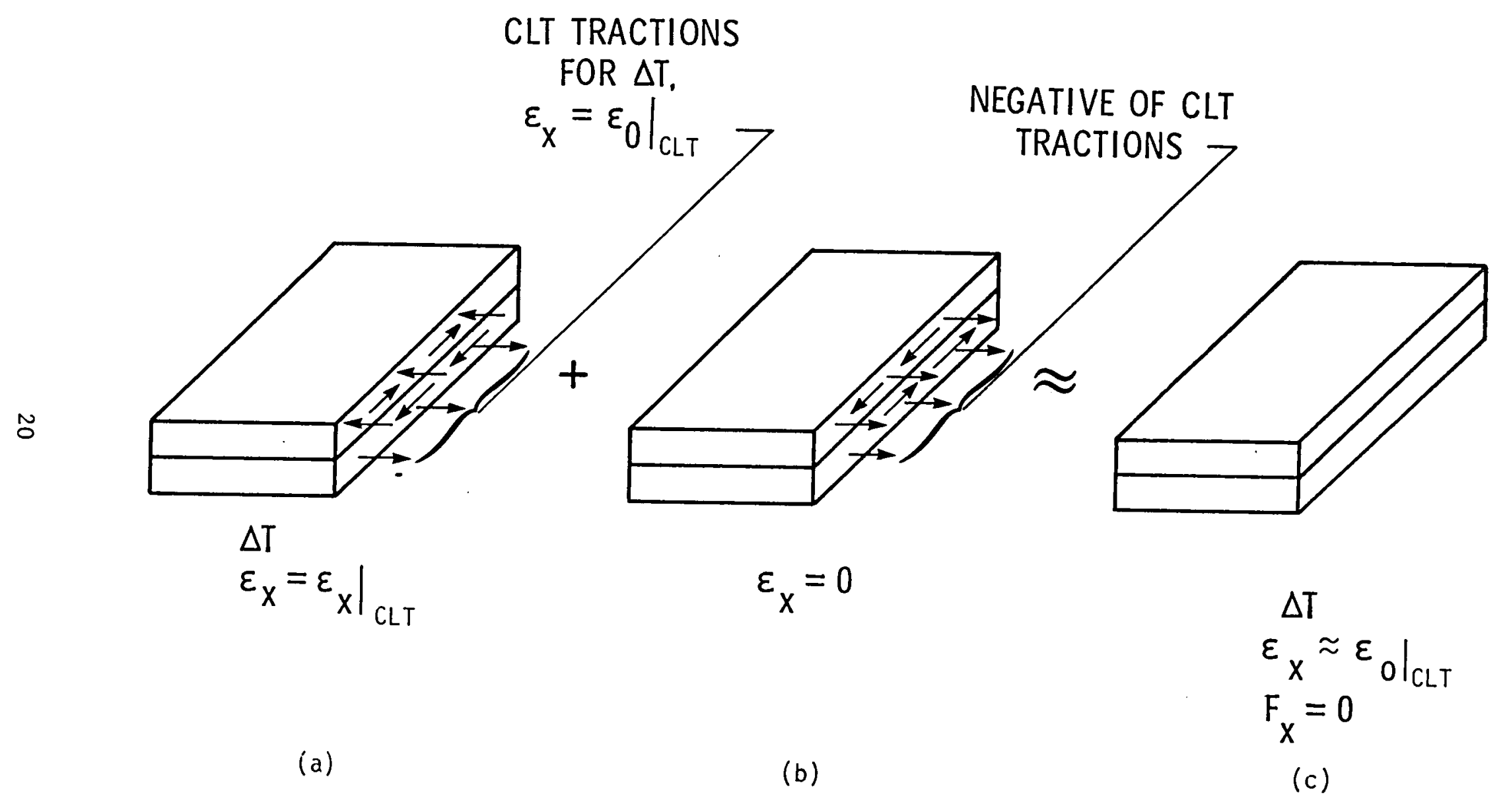

Fig. 4--Approximate superposition technique for thermal analysis. 


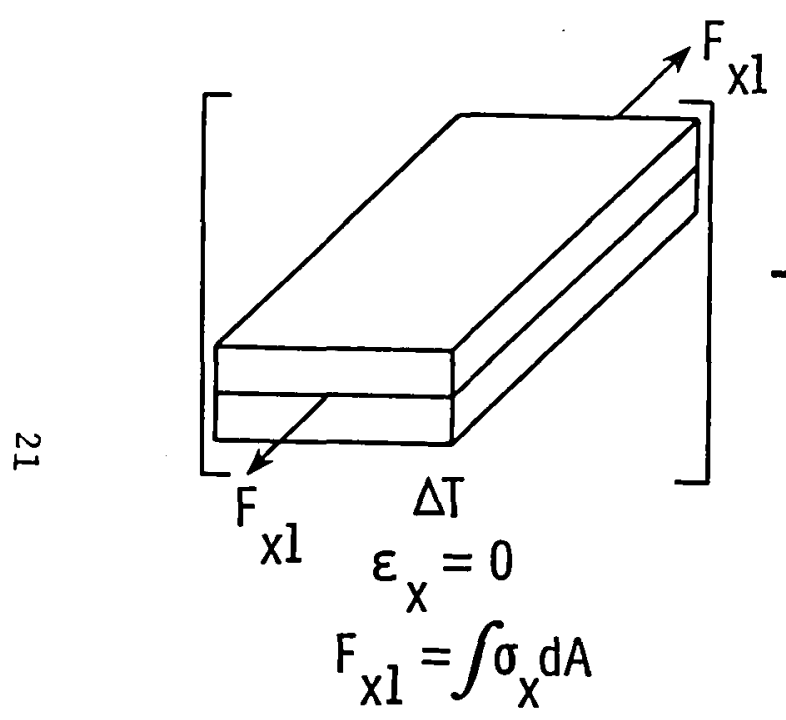

(a)

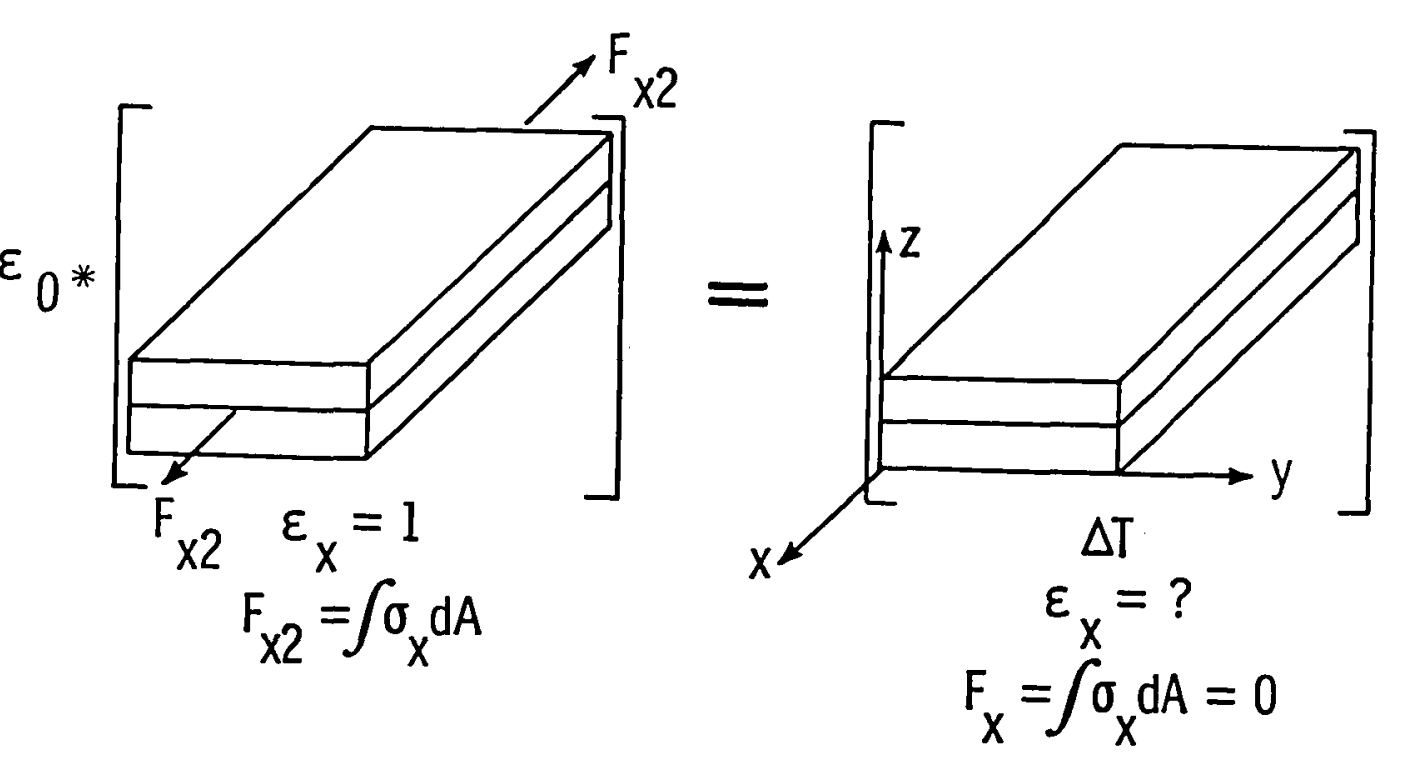

(b)

(c)

Fig. 5--Analysis of free-edge stresses due to thermal loads. 


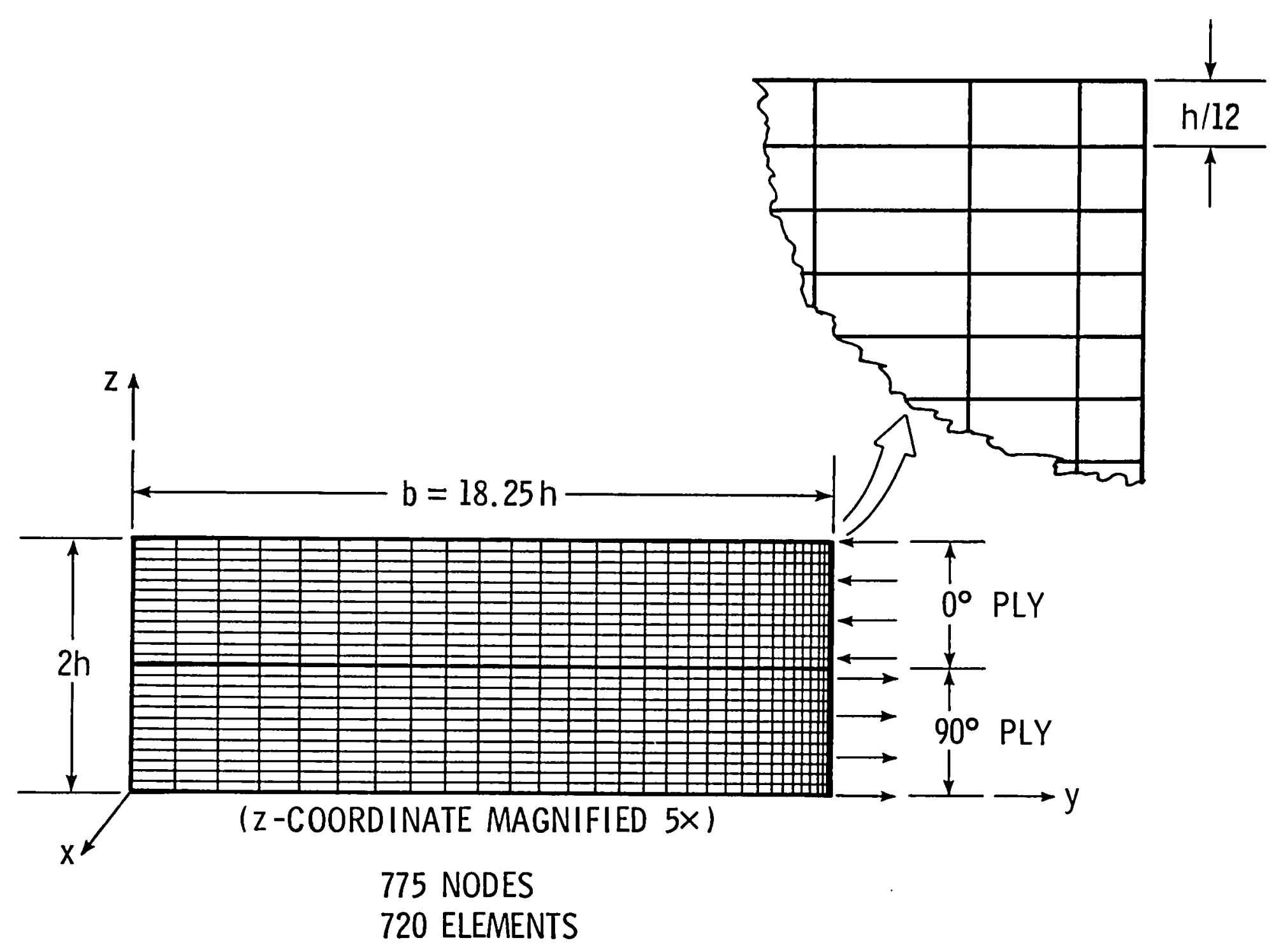

Fig. 6--Typical finite-element idealization for a $[0 / 90]_{S}$ laminate. 


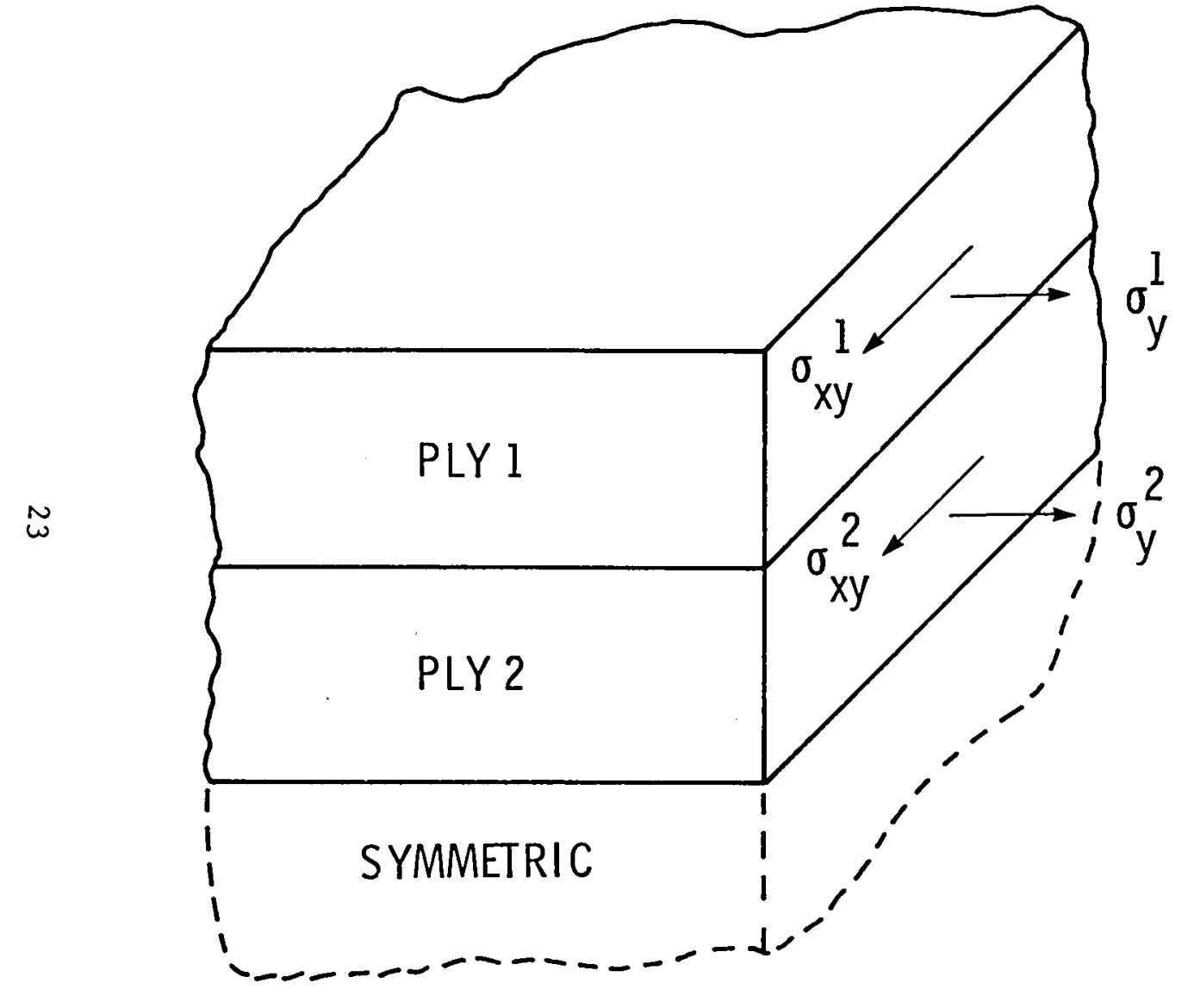

\begin{tabular}{|c|c|c|}
\hline \multicolumn{3}{|c|}{$\begin{array}{c}\text { EDGE TRACTIONS, MPa } \\
\varepsilon_{0}=0.001\end{array}$} \\
\hline \multirow{2}{*}{ COMPONENT } & \multicolumn{2}{|c|}{ LAMINATE } \\
\cline { 2 - 3 }$[0 / 90]_{s}$ & {$[ \pm 45]_{s}$} \\
\hline$\sigma_{y}^{l}$ & -2.474 & 0 \\
$\sigma_{x y}^{1}$ & 0 & -7.957 \\
$-\frac{2}{\sigma_{y}^{2}}-$ & 2.474 & 0 \\
$\sigma_{x y}^{2}$ & 0 & 7.957 \\
\hline
\end{tabular}

Fig. 7--Edge tractions for mechanical loading (i.e., $\varepsilon_{X}=\varepsilon_{0}$ ) of $[0 / 90]_{S}$ and $[ \pm 45]_{S}$ laminates. 


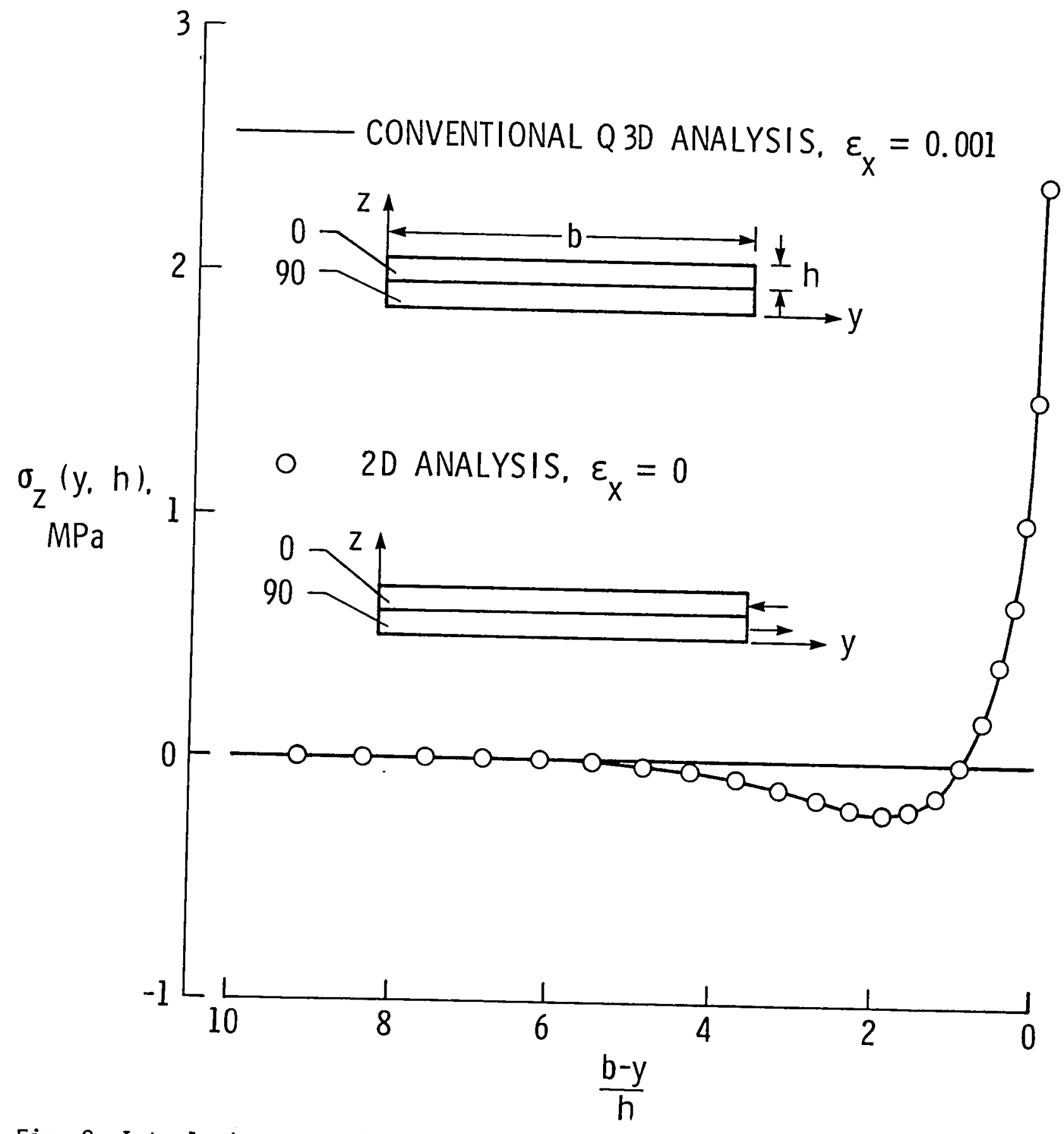
Fig. 8--Interlaminar normal stress along $z=h$ in $[0 / 90]_{S}$ laminate subjected
to mechanical load. 


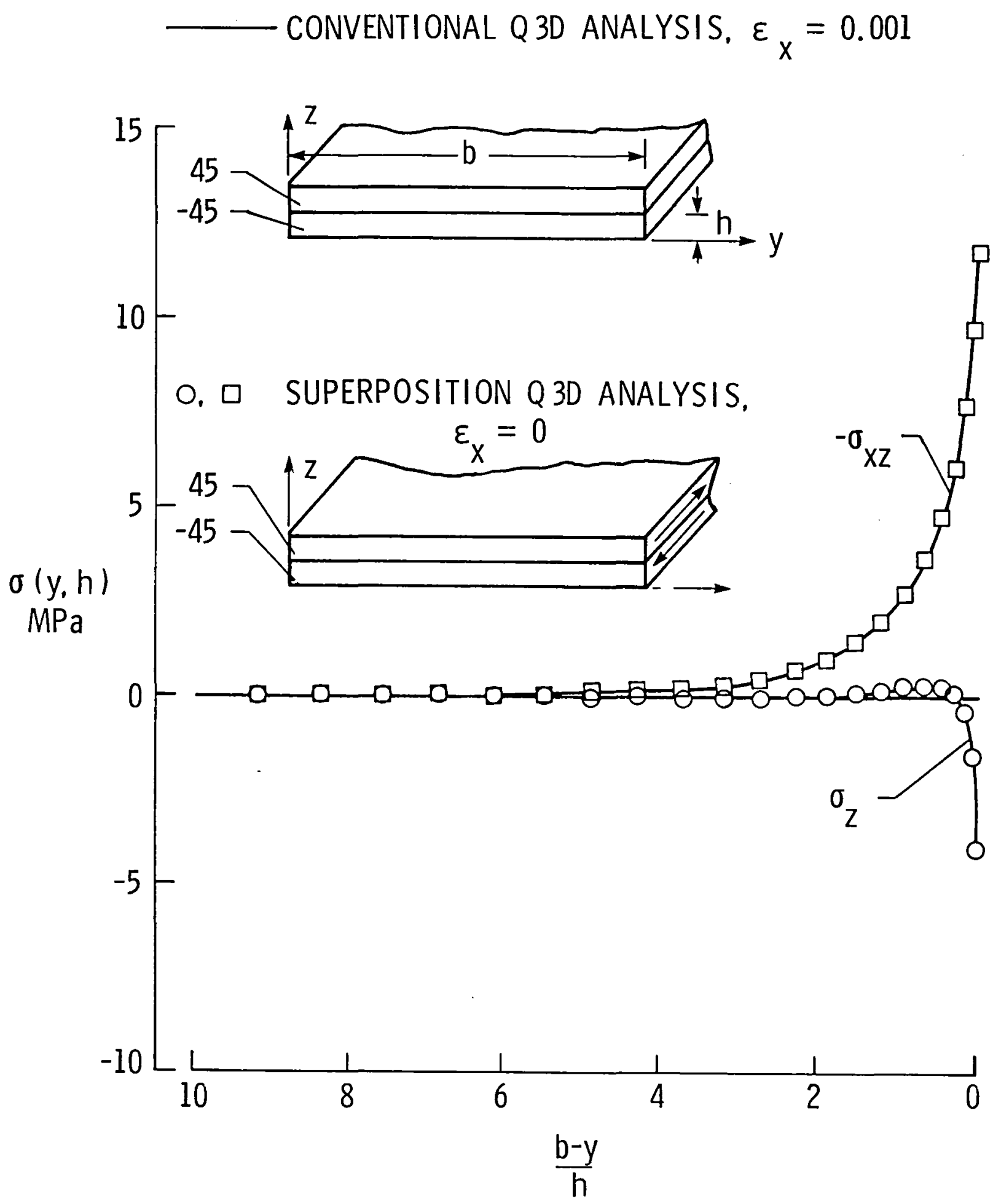
Fig. 9--Interlaminar normal and shear stress along $z=h$ in $[ \pm 45]_{s}$ laminate
subjected to mechanical load. 


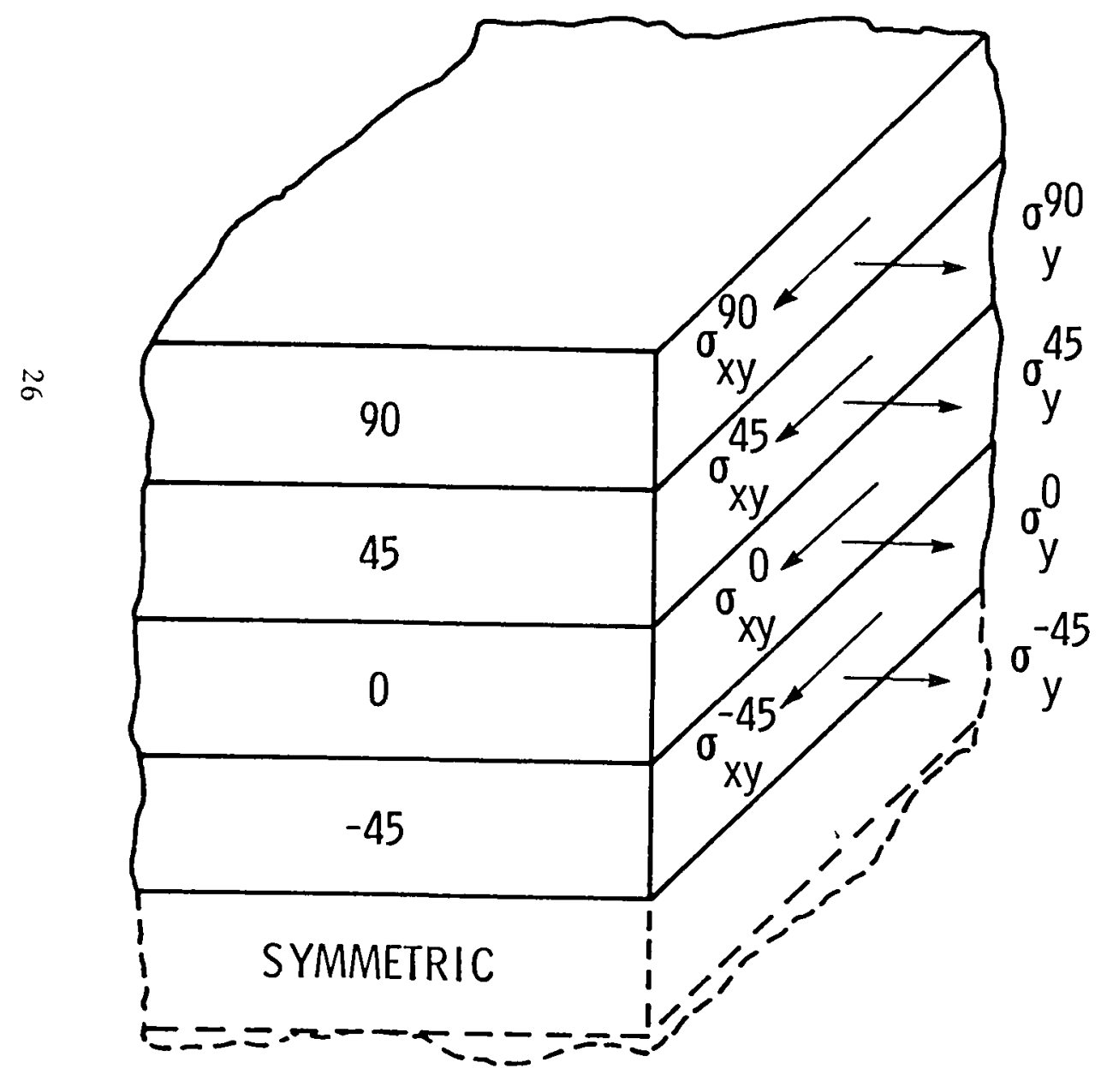

\begin{tabular}{|c|c|c|}
\hline \multicolumn{3}{|c|}{ EDGE TRACTIONS, MPa } \\
\hline \multirow[b]{2}{*}{ COMPONENT } & \multicolumn{2}{|c|}{ LOADING } \\
\hline & $\begin{array}{c}\text { MECHANICAL } \\
\varepsilon_{0}=0.001\end{array}$ & $\begin{array}{c}\text { THERMAL } \\
\Delta \mathrm{T}=-1.0^{0} \mathrm{~K}\end{array}$ \\
\hline$\sigma_{y}^{90}$ & 38.89 & 0.3584 \\
\hline$\sigma_{x y}^{90}$ & 0 & 0 \\
\hline$\sigma_{y}^{45}-$ & $\begin{array}{c}----- \\
-20.12\end{array}$ & $-\frac{-}{0}-$ \\
\hline$\sigma_{x y}^{45}$ & -21.61 & 0.3584 \\
\hline$\sigma_{y}^{0}$ & $--\frac{-}{1.349}$ & -0.3584 \\
\hline$\sigma_{x y}^{0}$ & 0 & 0 \\
\hline$\sigma_{y}^{-45}$ & $-\overline{-20.12}$ & $-\frac{-}{0}$ \\
\hline$\sigma_{x y}^{-45}$ & 21.61 & -0.3584 \\
\hline
\end{tabular}
Fig. 10--Edge tractions for mechanical and thermal loading of $[90 / 45 / 0 /-45]_{S}$
laminate (calculated using classical laminate theory). 


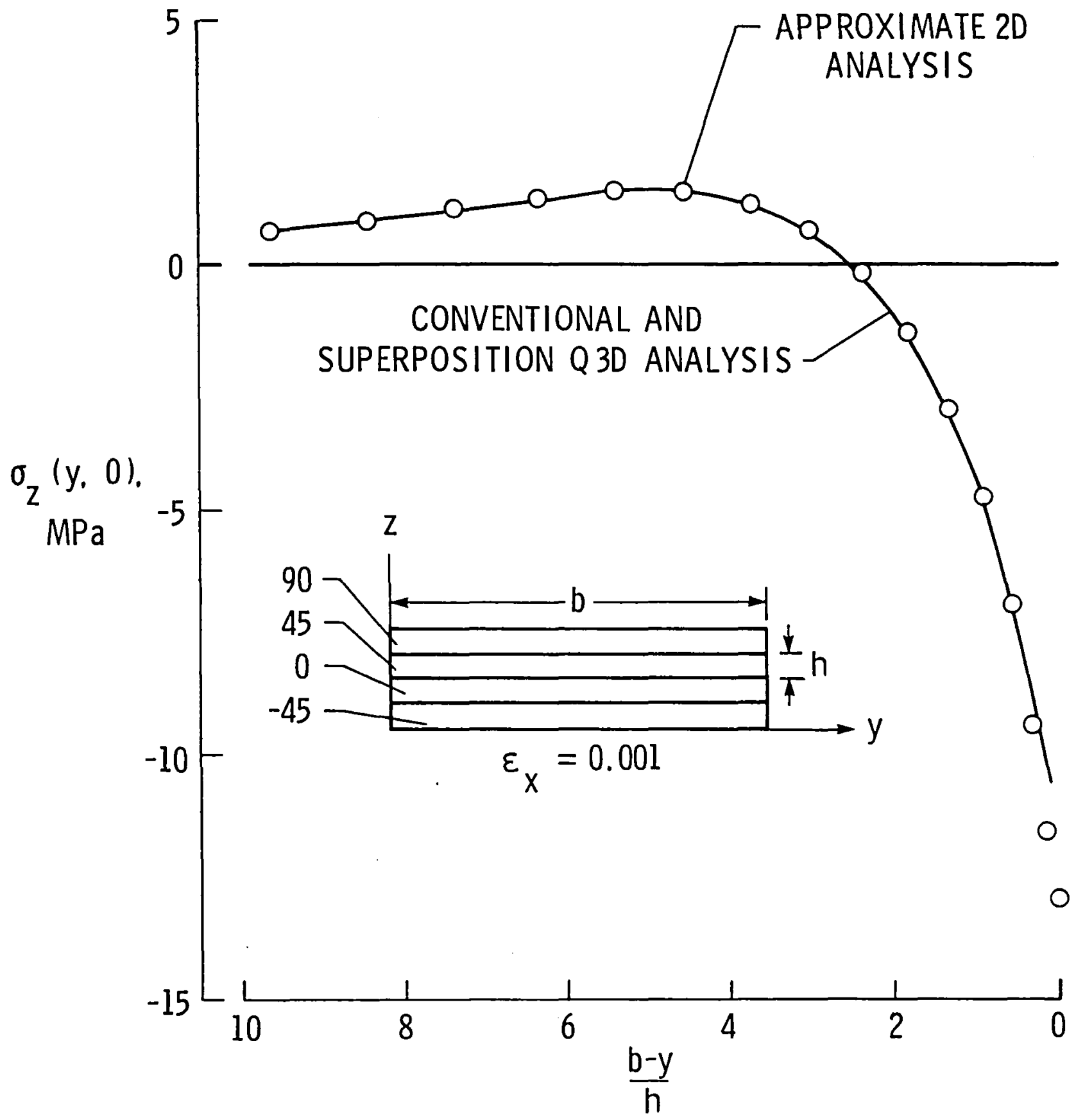

Fig. 11--Interlaminar normal stress along $z=0$ in $[90 / 45 / 0 /-45]_{s}$ laminate subjected to mechanical load. 


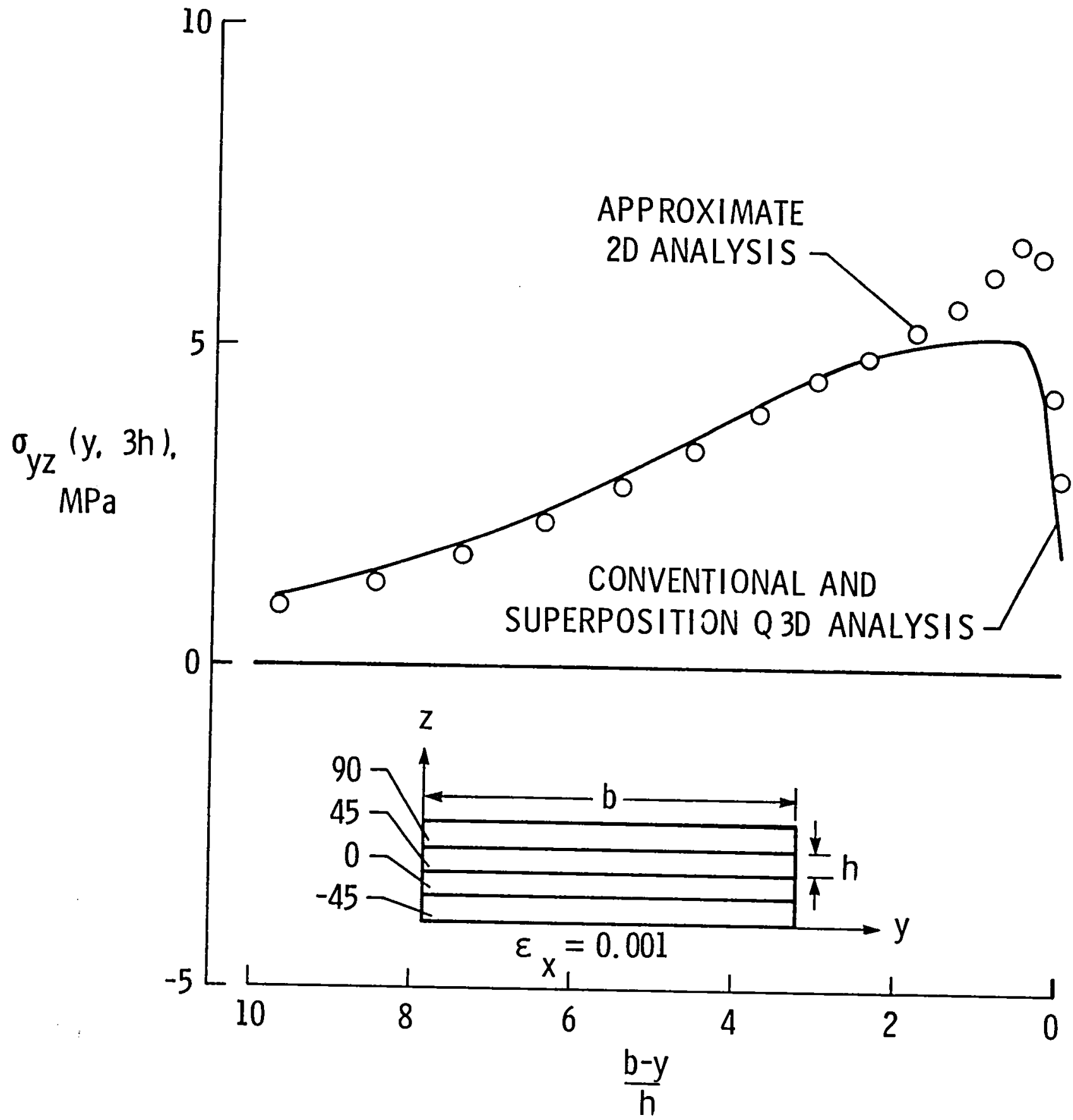
Fig. 12--Interlaminar shear stress along $z=3 \mathrm{~h}$ in $[90 / 45 / 0 /-45]_{s}$ laminate
subjected to mechanical load. 


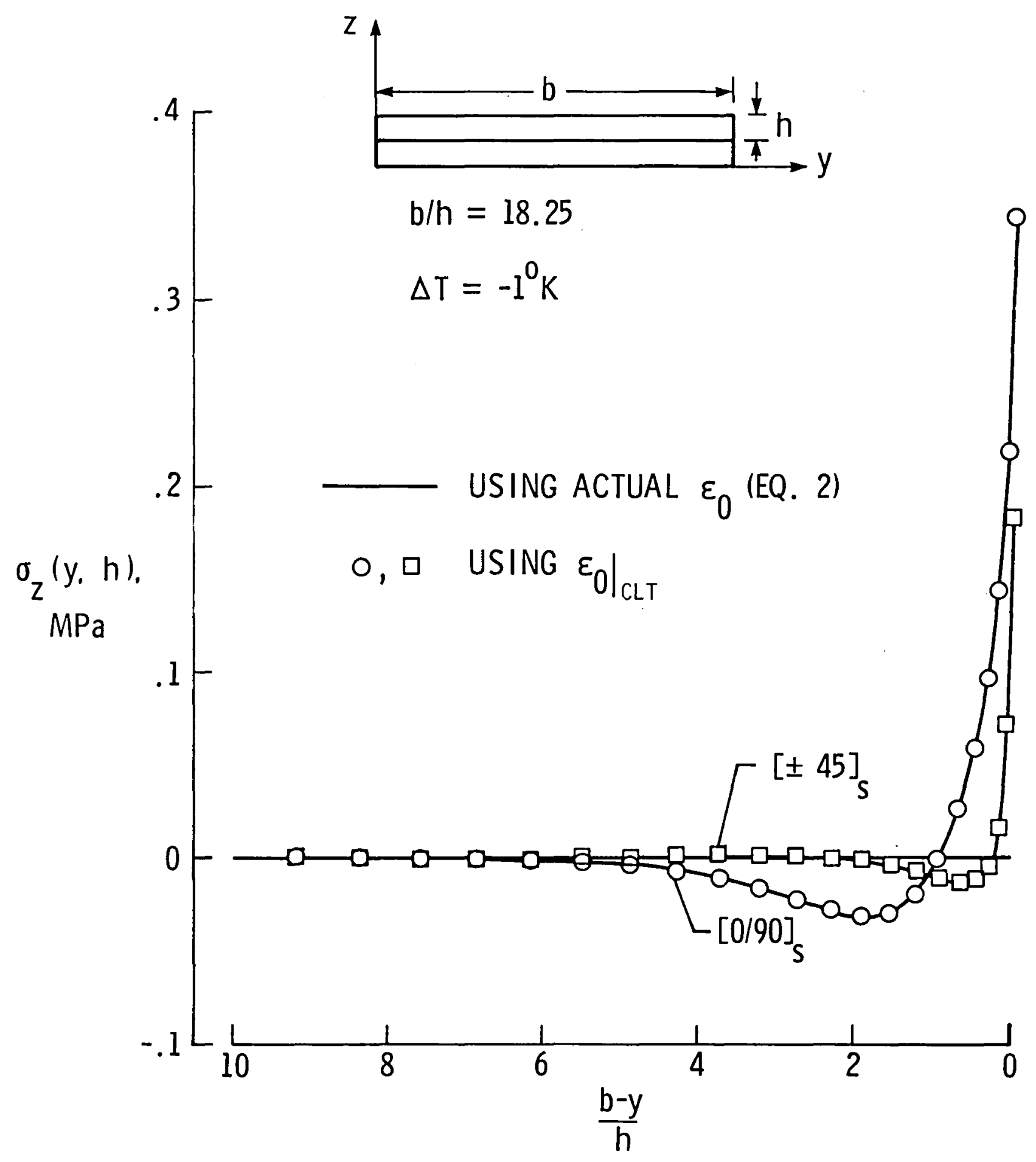
Fig. 13--Interlaminar normal stress along $z=h$ in $[0 / 90]_{S}$ and $[ \pm 45]_{s}$ laminates
due to thermal load. 


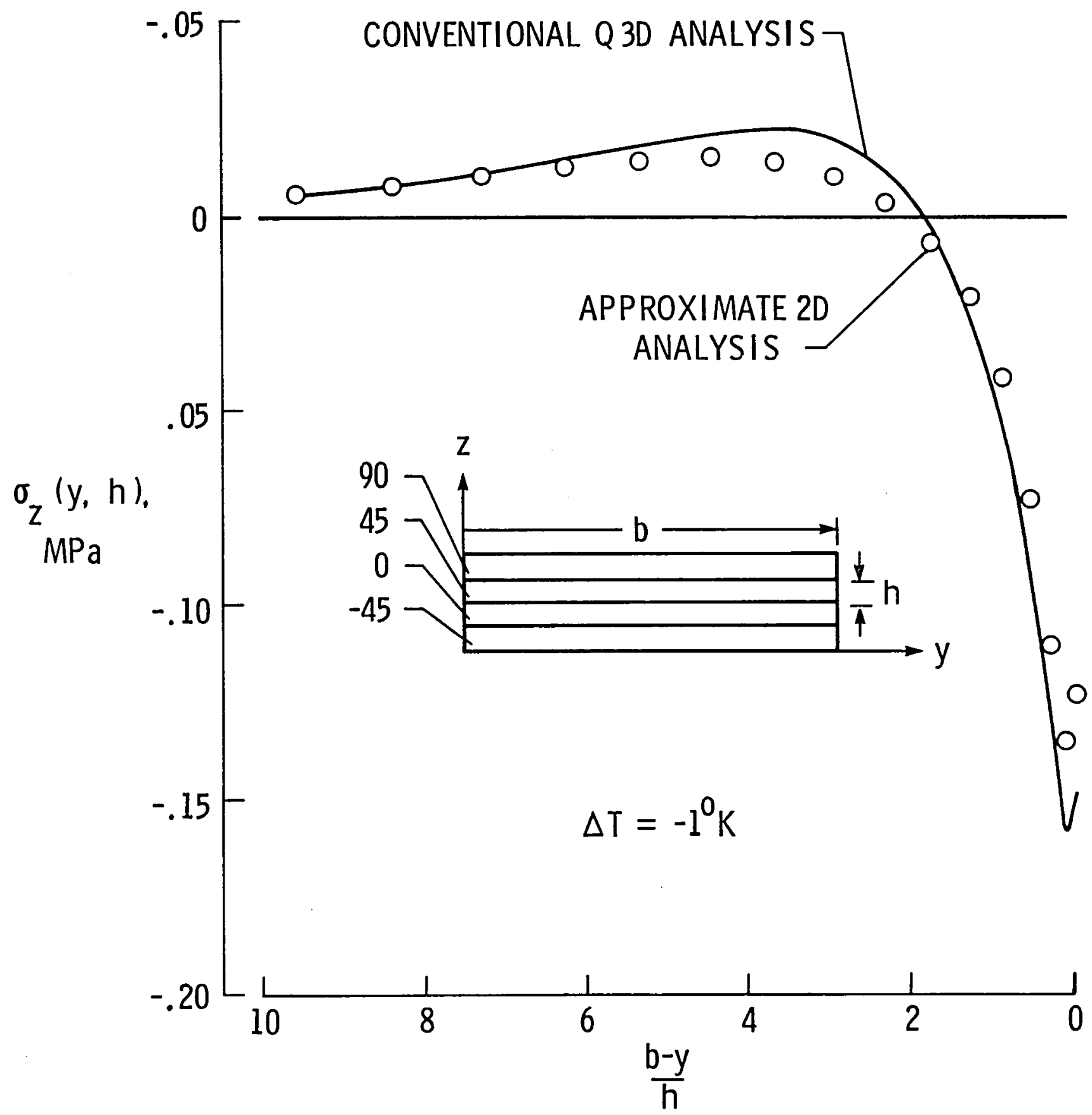

Fig. 14--Interlaminar normal stress along $z=h$ in $[90 / 45 / 0 /-45]_{S}$ laminate subjected to thermal load. 


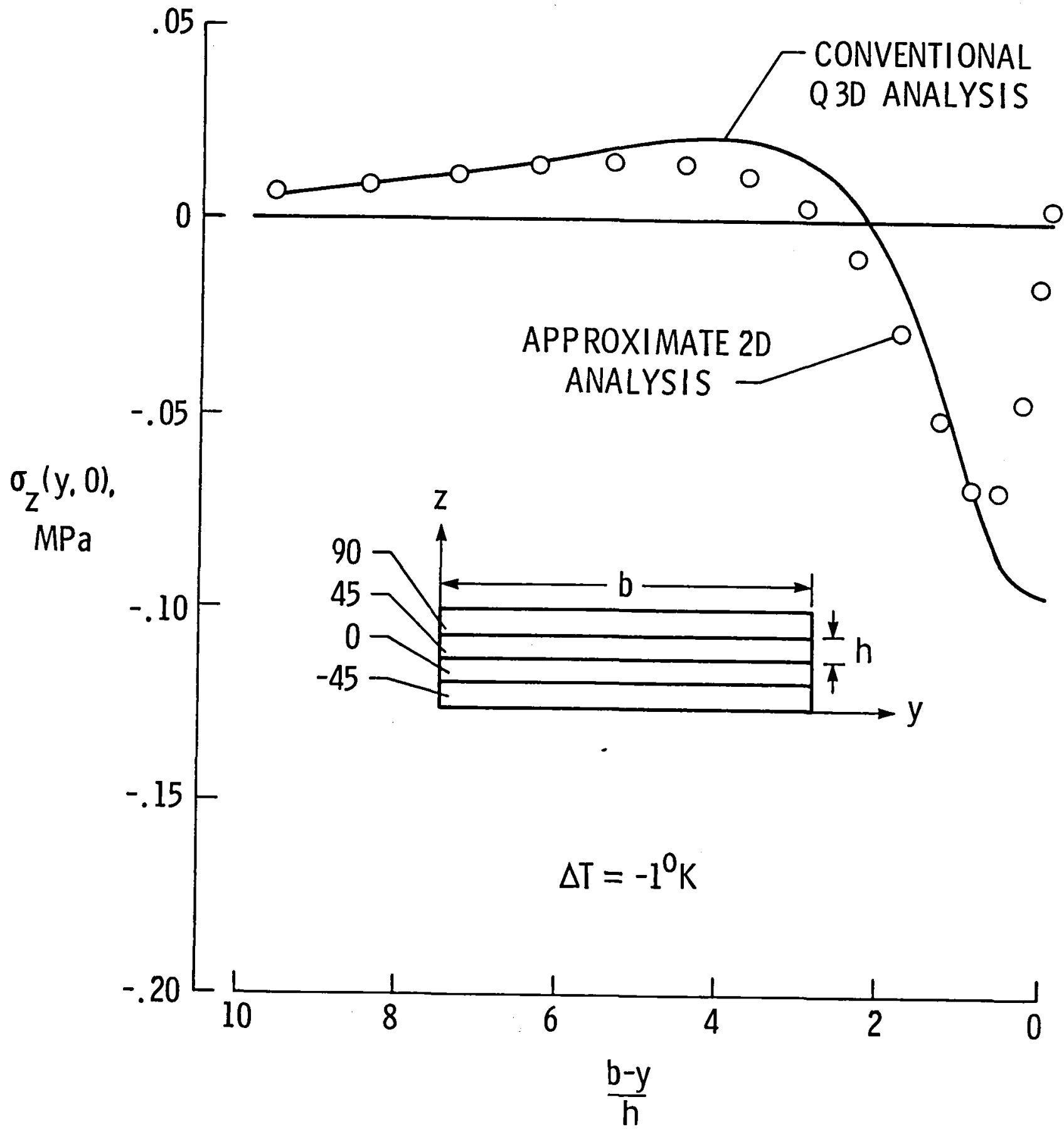

Fig. 15--Interlaminar normal stress along midplane in $[90 / 45 / 0 /-45]_{S}$ laminate
subjected to thermal load. 


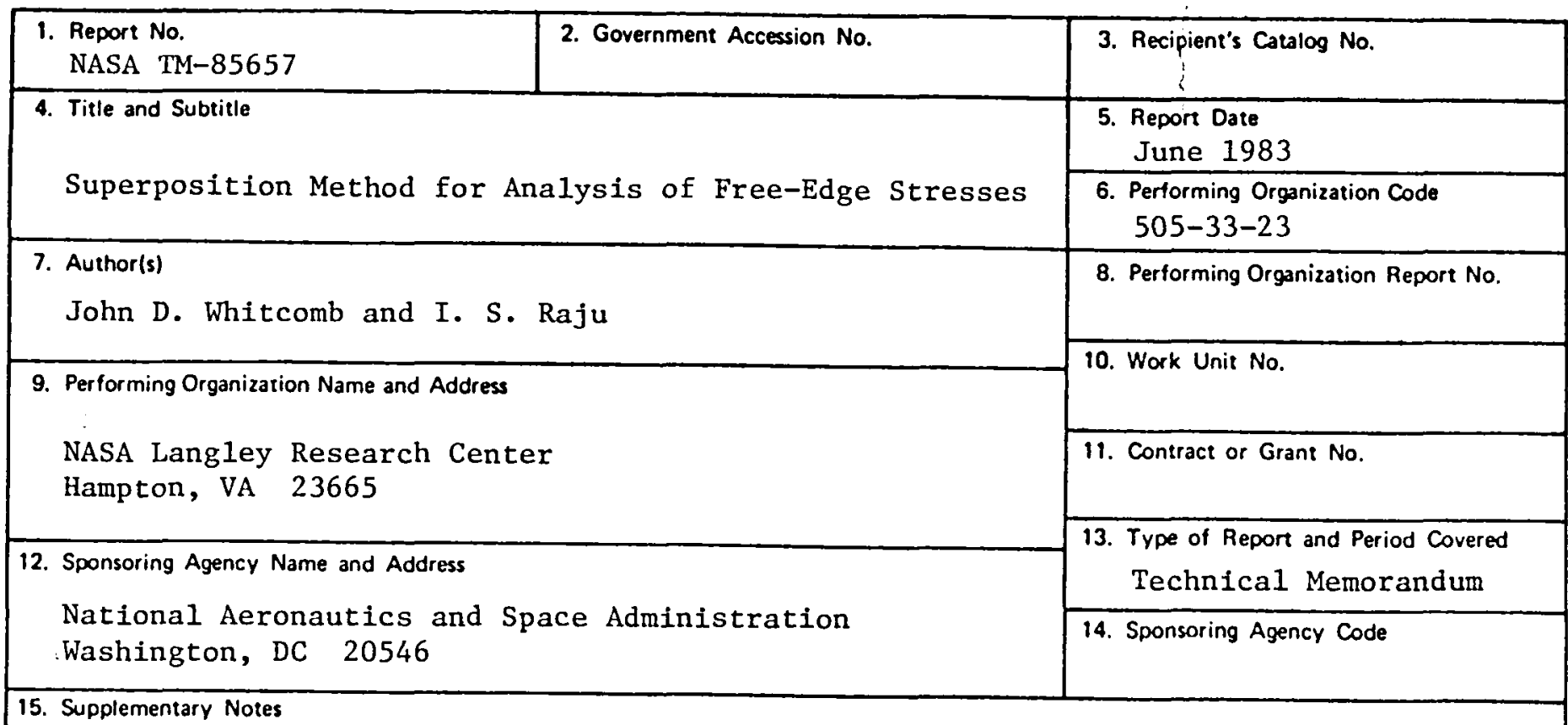

16. Abstract

Superposition techniques were used to transform the edge stress problem for composite laminates into a more lucid form. By eliminating loads and stresses not contributing to interlaminar stresses, the essential aspects of the edge stress problem are easily recognized. Transformed problem statements were deve1oped for both mechanical and thermal loads. Also, a technique for approximate analysis using a two-dimensional plane strain analysis was developed. Conventional quasi-three-dimensional analysis was used to evaluate the accuracy of the transformed problems and the approximate two-dimensional analysis. The transformed problems were shown to be exactly equivalent to the original problems. The approximate two-dimensional analysis was found to predict the interlaminar normal and shear stresses reasonably well.

17. Key Words (Suggested by Author(s))

Composite laminates

Interlaminar stresses

Finite element

Stress analysis
18. Distribution Statement

Unclassified - Unlimited

Subject Category 24
19. Security Classif. (of this report)

Unclassified
20. Security Classif. (of this page)

Unclassified
21. No. of Pages

32
22. Price

$\mathrm{AO} 3$ 
? 
